DOI: $10.15587 / 2706-5448.2021 .225328$

Article type «Reports on Research Projects»

\section{Andrei Torsky, Alexander Volnenko, Leonid Plyatsuk, Larysa Hurets, Daulet Zhumadullayev, Ahay Abzhahparov}

\title{
STUDY OF DUST COLLECTION EFFECTIVENESS IN CYCLONIC-VORTEX ACTION APPARATUS
}

The object of research is the efficiency of dust collection of fine dust in an apparatus with an intense turbulent mode of phase interaction. One of the most problematic areas of the existing dust and gas cleaning equipment is the low efficiency of collecting fine dust. Effective cleaning of exhaust gases from dust involves the use of multistage cleaning systems, including wet and dry dust cleaning devices, which entails high capital and operating costs. These disadvantages are eliminated in the developed design of the cyclone-vortex dust collector with two contact zones. The device implements both dry and wet dust collection mechanisms, which allows for high efficiency of dust removal at high productivity.

The conducted studies of the total and fractional efficiency of dust collection when changing the operating parameters of the developed device showed that the efficiency of collecting fine dust is 98-99\%. The increase in the efficiency of dust collection in the dry stage of the device is due to an increase in centrifugal force. In the wet stage of contact, the efficiency reaches its maximum values due to the vortex crushing of the liquid in the nozzle zone of the apparatus. Studies of the fractional efficiency of the apparatus show that with an increase in the diameter of the captured particles, the efficiency of the dust collection process for dry and wet stages, as well as the overall efficiency, increases. With an increase in the density of irrigation, the overall efficiency of dust collection in the apparatus increases. It has been established that an increase in the efficiency of capturing highly dispersed particles occurs due to turbulent diffusion, the value of which is determined by the frequency of turbulent pulsations and the degree of entrainment of particles during the pulsating motion of packed bodies. To describe the results obtained, a centrifugal-inertial model for a dry contact stage and a turbulent-diffusion model of solid particle deposition for a wet contact stage are proposed, which make it possible to calculate the dust collection efficiency of the contact stages, as well as the overall efficiency of the cyclone-vortex apparatus.

The results obtained show the prospects of using devices of this design at heat power plants and other industries.

Keywords: dust and gas emissions, complex cleaning, centrifugal force, regular packing, vortex interaction, dust collection efficiency.

\section{Introduction}

The growth in the scale of economic activity leads to increased anthropogenic impact and imbalance in the environment. Along with the depletion of natural resources, environmental pollution, especially water resources and atmospheric air, is increasing. This significantly undermines the natural resource potential of the state's development, negatively affects the welfare and health of the population, and also poses a threat to environmental safety [1,2].

The growing demand for electricity and heat leads to an increase in their production, which negatively affects the environment and increases the risk of disease for the population living in the zone of influence of thermal power plants (TPPs) [3-5]. Consuming natural resources, thermal power enterprises are sources of complex environmental pollution. The activity of TPPs has a negative impact on the state of ecosystems of the adjacent territories [6-8]. The deposition of pollutants from gas emissions leads to soil pollution and migration of heavy metals into groundwater and surface waters [9-11]. This poses the task of developing environmental protection measures to protect the atmospheric air from emissions from heat generating enterprises $[12,13]$. One of the ways to reduce the amount of dust and gas emissions from TPPs is to increase the efficiency of gas cleaning equipment.

The choice of gas cleaning equipment should take into account a number of factors: physical and chemical characteristics of the carrier gas, characteristics of chemical and solid pollutants [14-16]. Complex pollution of waste gases from TPPs from gaseous substances and solid particles requires the use of multistage cleaning systems, including dry and wet cleaning devices, which increases capital and operating costs $[17,18]$. Apparatus for complex purification of off-gases, operating in the regime of developed turbulence, are promising for solving this problem.

Analysis of the mechanisms of dust deposition shows that in those cases when the energy of a continuous (gas) 
flow is used to intensify the dust collection process in gasliquid systems, the most effective are centrifugal and vortex interaction of flows [19]. In this case, a highly developed interface is created, and the dust particles are affected by the inertial force and centrifugal force, which significantly exceed the force of gravity. A large number of devices have been developed to implement these deposition mechanisms. So, for the process of dust collection based on the centrifugal interaction of flows, the operation of various types of cyclones is based, allowing to capture dust in dry form, and in the presence of irrigation - centrifugal dust collectors with central and peripheral irrigation [20, 21].

Apparatuses with a regular movable nozzle are an example of vortex interaction of flows. In them, the packing bodies are mounted on flexible strings with fixed steps in the vertical and radial directions in the volume of the contact zone. In devices with a regular movable nozzle, the principle of creating an in-phase mode of interacting phases is laid. Such a design-mode solution, as shown by preliminary studies, leads to a significant intensification of the ongoing processes [21]. With regard to dust collection, the regular placement of packed bodies of various geometric shapes makes it possible to implement inertial and diffusion deposition of solid particles on films located on the surface of the packed bodies and drops, filling the entire working space of the contact area. The hydraulic resistance of devices with a regular movable nozzle is an order of magnitude lower than that of devices of percussion or centrifugal action, while the efficiency of cleaning dust particles larger than 5 microns is over $99 \%$ [22].

Constructive solutions for the implementation of centrifugal and vortex interaction of flows in one apparatus led to the development of a new design of the dust collector.

The authors of this work have developed a design of a dust collector with two contact zones, capable of simultaneously implementing two dust collection mechanisms - centrifugal in the lower zone and vortex in the upper contact zone. In this case, dust in the lower stage of contact is captured in dry form, and its additional capture occurs in the wet degree of contact. A wet step is a packing area in which packing bodies are mounted on flexible strings with fixed vertical and radial pitches. The regular arrangement of the packing elements in the volume of the contact zone makes it possible to achieve the in-phase regime of the interacting phases [22, 23], which leads to a significant intensification of the ongoing processes. However, the results of research and calculation of such a dust collector are absent, which confirms the relevance of this work.

Thus, the object of research is the efficiency of dust collection of fine dust in an apparatus with an intense turbulent regime of phase interaction. The aim of research is to obtain theoretical and experimental data on the total and fractional efficiency of dust collection, depending on the operating parameters of the equipment.

\section{Methods of research}

The experimental installation for conducting research on the efficiency of dust collection included:

- cyclone-vortex dust collector;

- fan;

- pump;

- circulating and pressure vessels of the liquid for irrigation of the upper contact stage;
- container for collecting dry dust from the lower stage of contact;

- compressor for spraying dust at the entrance to the dust collector.

In all experiments, the dust concentration at the inlet to the apparatus was maintained at about $2 \mathrm{~g} / \mathrm{m}^{3}$. The standard dust was KP-3 pulverized quartz, additionally milled in a vibrating mill [24].

When determining the overall efficiency of the dust collection process, the method of internal filtration was used [24]. Glass wool was used to fill the adapter. The gas flow rate through the adapter was set based on the condition of isokinetic sampling. To measure the dispersed composition of dust in a gas flow, an impactor was used instead of adaptors.

The object under study was a cyclone-vortex dust collector (Fig. 1). The device includes a body 1, nozzles 2 and 3 , respectively, for gas inlet and outlet. In the working area of the apparatus there are support-distribution grids 6 , strings 7 with nozzle bodies fixed on them 8 . The irrigation liquid is injected into the upper stage through the sprinkler 4, the spent absorber is drained through the fitting 5 . The upper and lower contact stages are separated by an inclined partition 9 with a central tube 10 mounted in it, located coaxially with the housing of the lower contact stage. The upper cut of the central pipe is equipped with a cap 11. The lower stage of contact has a conical bottom 12 with a branch pipe for removing the captured dust 13 .
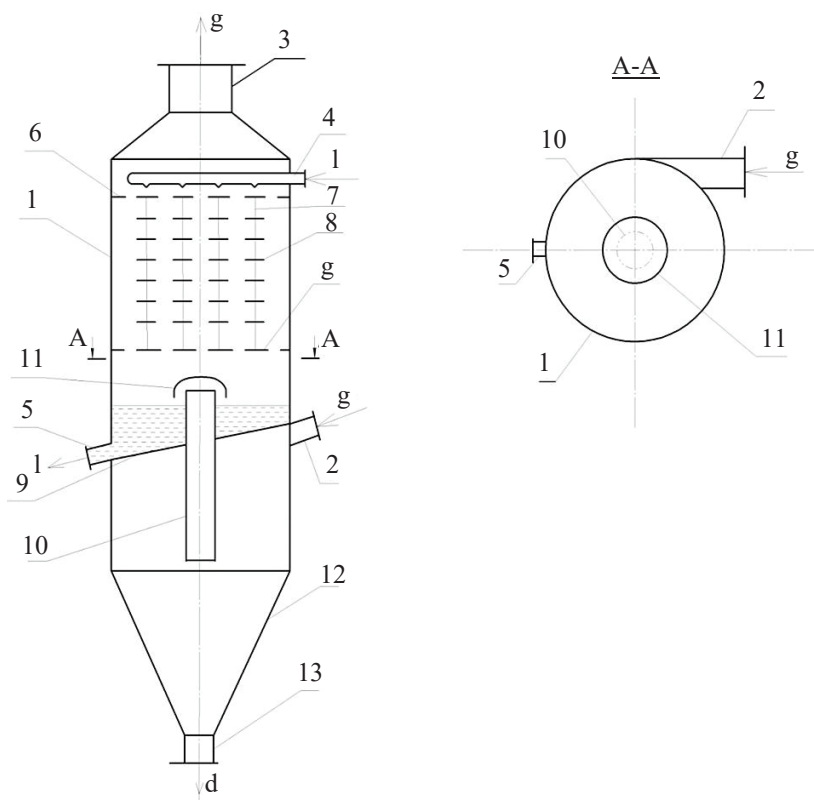

Fig. 1. Dust collector of cyclonic-vortex action: 1 - body; 2 - gas inlet pipe; 3 - gas outlet pipe; 4 - sprinkler; 5 - nozzle for draining the spent absorber; 6 - support and distribution grid; 7 - strings; 8 - packing bodies; 9 - inclined partition; 10 - central pipe; 11 - cap;

12 - conical bottom; 13 - branch pipe for removal of trapped dust

The gas flow entering the purification is supplied through the nozzle 2, installed tangentially in the lower part of the apparatus.

With the tangential supply of the gas flow, a centrifugal force arises, which acts on solid dust particles, pressing them against the inner wall of the apparatus 1 . Under the action of gravity, the solid dust particles slide into the conical bot- 
tom 12 of the lower contact stage and are removed from the apparatus through the branch pipe 13. Cleaned from dust the gas flow through the upper cut of the central pipe 10 enters the upper contact stage. At the entrance to it, the central pipe 10 is equipped with a cap 11 to prevent the ingress of flowing irrigation liquid. The lower and upper stages of the contact are separated by an inclined partition 9 , as a result of which they work autonomously.

The operation of the upper stage of contact occurs in a counter-current mode. In this case, the gas flow coming from below interacts with the scrubbing liquid supplied through the sprinkler 4 in the volume of the packing zone. The arrangement of the packing elements 8 on the strings 7 is made with a step in the vertical direction, ensuring the achievement of the mode of simultaneous vortex formation (in-phase mode). The purified gas flow is removed from the apparatus through the nozzle 3 , and the liquid spent in the upper stage is removed through the nozzle 5 .

\section{Research results and their discussion}

Fig. 2-4 show the results of studies in the form of graphs of the dependences of the dust collection efficiency of the dry stage and wet stages, as well as the overall dust collection efficiency of the cyclone-vortex apparatus on the gas velocity, wet stage irrigation density and the dispersed composition of dust.

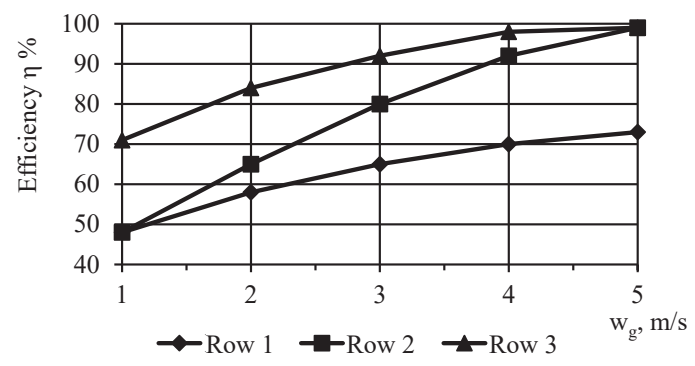

Fig. 2. Dependence of the efficiency of dust collection on the gas velocity in the upper stage of the contact: $t_{u} / b=2 ; t_{p} / b=2 ; b=0.04 \mathrm{~m}$; $L=25 \mathrm{~m}^{3} / \mathrm{m}^{2} \mathrm{~h}$; Row $1-\eta_{c} ;$ Row $2-\eta_{m i}$ Bow $3-\eta_{\text {total }}$

As seen from Fig. 2, with an increase in the gas flow rate, the dust collection efficiency of the dry and wet stages, as well as the overall efficiency, increases. The increase in the efficiency of the dry stage is due to the increase in centrifugal force. In the wet stage of contact, the efficiency reaches its maximum values in the drip mode, after which a further increase in the gas velocity leads to the entrainment of liquid from the apparatus and the efficiency of the process decreases somewhat.

High values of the degree of dust collection are achieved due to the vortex crushing of the liquid in the nozzle zone of the apparatus. The frequency of vortex stripping from the packing elements, as well as the intensity and frequency of pulsations, increase in proportion to the gas velocity. The pulsating motion of the packing intensifies the process of breaking off the liquid film and its subsequent crushing into smaller droplets. This increases the contact surface of the phases, and, ultimately, the overall efficiency of dust collection.

With an increase in the irrigation density of the wet contact stage (Fig. 3), the increase in the efficiency of the packed (curve 1) zone and the overall efficiency of dust collection (curve 2) occurs in proportion to the amount of liquid supplied to the packed zone. In this case, the amount of liquid retained by the packing increases, the total number of crushed drops increases, which contributes to the growth of the interface and the degree of dust collection.

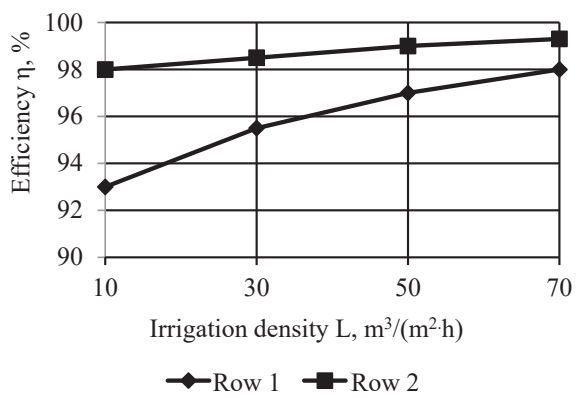

Fig. 3. Dependence of the efficiency of dust collection on the density of irrigation in the upper stage of contact: $t_{u} / b=2 ; t_{p} / b=2 ; b=0.04 \mathrm{~m}$; $L=25 \mathrm{~m}^{3} / \mathrm{m}^{2} \mathrm{~h} ; w_{g}=4 \mathrm{~m} / \mathrm{s}$; Row $1-\eta_{m i}$ Row $2-\eta_{\text {total }}$

Studies of the fractional efficiency of the cyclone-vortex action apparatus are shown in Fig. 4. The results show that with an increase in the diameter of the captured particles, the efficiency of the dry and wet dust collection process, as well as the overall efficiency, increases.

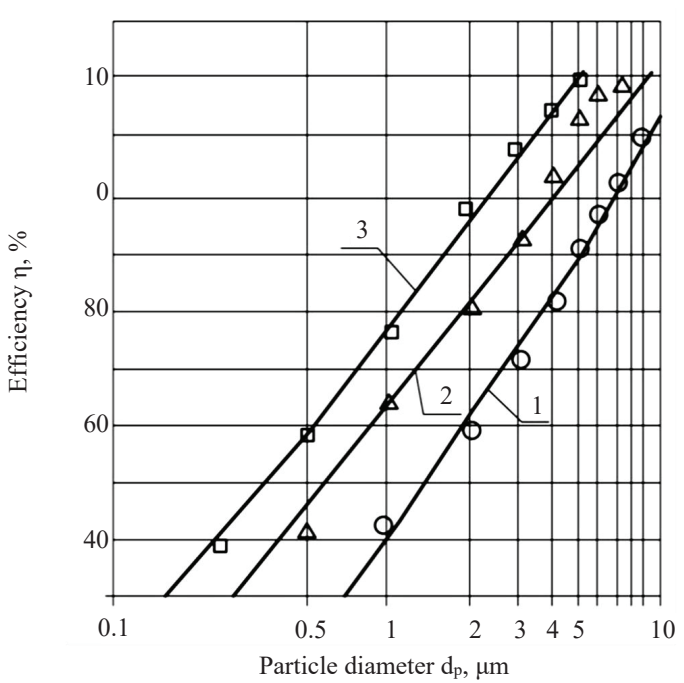

Fig. 4. Dependence of the efficiency of dust collection on the dispersed composition of dust particles: $1-\eta_{c i} 2-\eta_{m i} 3-\eta_{\text {total }}$

Increasing the gas velocity or the amount of liquid in the wet stage will also increase fractional efficiency.

This regularity is observed for any dust fractions. Naturally, the absolute value of the coefficient of dust collection of large particles is greater than of small ones, but the degree of collection of the latter increases more significantly with increasing gas velocity. This is explained by the analysis of the mechanism of particle trapping [25, 26]. For particles with a diameter $d_{p}>5 \mu \mathrm{m}$, the prevailing effect is exerted by inertia forces, and for $d_{p}<2 \mu \mathrm{m}$, by diffusion forces. It is obvious that an increase in the efficiency of capturing highly dispersed particles occurs due to turbulent diffusion, the value of which is determined by the frequency of turbulent pulsations and the degree 
of particle increase. The main contribution to the pulsation frequency is made by the process of vortex motion of the gas-liquid layer, which leads to multiple stripping of the liquid film from the packing elements and crushing it into small drops. In this case, the contact surface of the phases and the efficiency of dust collection increase.

To obtain the calculated dependence of the efficiency of dust collection of the dry stage, a centrifugal-inertial model was used. The deposition of particles in the dry stage of the cyclone-vortex apparatus occurs due to the combined action of two mechanisms: centrifugal, which moves particles to the walls of the apparatus, and inertial, which promotes the deposition of particles under the influence of gravity. To derive an equation describing the centrifugal sedimentation of dust particles in a dry stage, let's apply the method proposed by Light and Leaf [27]. The dust collection efficiency can be determined by the formula:

$$
\eta_{C}=1-\exp \left[-2\left(C_{k} \cdot \psi\right)^{1 /(2 n+2)}\right]
$$

where $C_{k}-$ a coefficient that depends on the design ratios of the dry stage of the apparatus.

For a dry step, the $C_{k}$ coefficient is calculated by the equation:

$$
\begin{aligned}
& C_{k}=\frac{\pi \cdot D_{c}^{2}}{a \cdot i_{1}} \cdot\left[1-\left(\frac{d}{D_{c}}\right)^{2}\right] \cdot\left(\frac{2 \cdot h_{T}}{D_{c}}-\frac{h_{i n}}{D_{c}}\right)+ \\
& +\left[\left(\frac{d}{D_{c}}\right)^{2}-\left(\frac{d_{1}}{D_{c}}\right)^{2}\right] \cdot\left(\frac{4 \cdot H_{c}}{D_{c}}+\frac{4 \cdot H_{k}}{D_{c}}\right) .
\end{aligned}
$$

The values of the constructive relationships in equation (2):

- height of the inlet pipe $a=0.66 \cdot D_{c}$;

- width of the inlet pipe $i n_{1}=0.26 \cdot D_{c}$;

- inner diameter of the central exhaust pipe $d=0.59 \cdot D_{c}$;

- inner diameter of the dust outlet $d_{1}=0.4 \cdot D_{c}$;

- the height of the central pipe $h_{T}=1.74 \cdot D_{c}$;

- the height of the outer part of the central pipe $h_{\text {in }}=0.3 \cdot D_{c}$;

- height of the cylindrical part of the lower stage $H_{c}=2.26 \cdot D_{c}$;

- the height of the conical part of the lower step $H_{k}=2 \cdot D_{c}$.

The quantity y in equation (1) is a modified inertial parameter that characterizes the state of the dust-gas mixture:

$$
\psi=\frac{d_{p}^{2} \cdot \rho_{p} \cdot W_{i n}}{18 \mu_{g} \cdot D_{c}}(n+1),
$$

where $W_{i n}$ - the gas velocity at the inlet to the dry stage, $\mathrm{m} / \mathrm{s} ; d_{p}-$ solid particle diameter, $\mathrm{m} ; \rho_{p}$ - particle density, $\mathrm{kg} / \mathrm{m}^{3} ; \mu_{G}-$ gas viscosity, Pa.s; $D_{c}$ - diameter of the cylindrical part of the apparatus, $\mathrm{m}$.

The value of $\mathrm{n}$ in equations (1) and (3) according to [28] is:

$$
n=1-\left(1-0.0165 \cdot D_{c}^{0.14}\right) \cdot\left(\frac{T_{g}}{283}\right)^{0.3},
$$

where $T_{g}$ - the absolute temperature of gases, $\mathrm{K}$.

To obtain the calculated dependence of the efficiency of dust collection of the wet stage, a turbulent-diffusion model of the sedimentation of solid particles was used.

A turbulent regime characterized by vortex formation is realized in the packed zone of devices with a regular packing structure. During the dust collection process, the gas stream contains solid particles of various sizes. As it is known, the capture of solid particles less than 0.1 microns in size occurs due to molecular diffusion.

Solid dust particles have a size much smaller than the scale of turbulent pulsations and therefore are involved in the pulsating motion of the gas flow. Moreover, the degree of entrainment also depends on the diameter and density of the particles, i. e., on its inertia. Consequently, when calculating the deposition efficiency in intense gas flow regimes, it is necessary to take into account, along with the inertial deposition mechanism and molecular diffusion, also turbulent diffusion, which makes a significant contribution to the efficiency of capturing particles with a size of $1-2 \mu \mathrm{m}$ and more

To derive the equation for the coefficient of turbulent diffusion, a dissipative approach was used:

To derive the equation for the coefficient of turbulent diffusion, a dissipative approach was used:

$$
\begin{aligned}
& D_{T}=B_{T} \cdot\left(\xi_{L}\right)^{1 / 3} \cdot\left(1-\varepsilon_{0}\right)^{1 / 3} \cdot\left(\frac{H}{t_{v}}\right)^{1 / 3} \cdot\left(\frac{\rho_{g}}{\rho_{l}}\right)^{1 / 3} \times \\
& \times\left(\frac{1}{h_{0}}\right)^{1 / 3} \cdot d_{k}^{4 / 3} \cdot u_{g} \cdot S t k,
\end{aligned}
$$

where $B_{T}=8.38 \cdot(1-\varphi)-$ correction factor; $\xi_{L}$ - resistance coefficient of the liquid phase; $\varepsilon_{0}$ - porosity of the bed of packing bodies; $H$ - height of the nozzle zone of the apparatus, $\mathrm{m} ; t_{v}$ - the vertical distance between the rows of the packing; $\rho_{g}$ - gas density, $\mathrm{kg} / \mathrm{m}^{3} ; \rho_{l}$ - liquid density, $\mathrm{kg} / \mathrm{m}^{3} ; h_{0}$ - height of the central pipe in the nozzle zone, $\mathrm{m} ; d_{k}-$ drop diameter, $\mathrm{m} ; u_{g}-$ gas velocity in the packed zone, $\mathrm{m} / \mathrm{s} ; S t k=\frac{\rho_{p} \cdot d_{p}^{2} \cdot u_{p}}{18 \mu_{g} \cdot d_{k}}-$ Stokes criterion.

Dust collection efficiency is determined by the formula:

$$
\eta^{m}=2.97 \cdot\left(\frac{W_{g} \cdot d_{k}}{D_{T}}\right)^{-1 / 4},
$$

where $W_{g}-$ gas velocity, $\mathrm{m} / \mathrm{s} ; D_{T}-$ coefficient of turbulent diffusion, $\mathrm{m}^{2} / \mathrm{s}$.

The total efficiency of the cyclone-vortex apparatus, taking into account the efficiency of dry and wet stages, can be calculated by the formula:

$$
\eta_{t o t}=1-\left(1-\eta_{c}\right)\left(1-\eta_{m}\right)
$$

The results of calculations by the formula (7) in the test mode parameters changes range from the experimental data is not more than $\pm 15 \%$.

\section{Conclusions}

As a result of the analysis of the most effective mechanisms for collecting dust, the design of a cyclone-vortex dust collector has been developed, which makes it possible to implement centrifugal and vortex mechanisms for collecting dust. The conducted studies of the overall and fractional efficiency of dust collection when changing the operating parameters of the developed apparatus showed that the efficiency of collecting fine dust is $98-99 \%$. To describe the results obtained, a centrifugal-inertial model for a dry contact stage and a turbulent-diffusion model 
of solid particle deposition for a wet contact stage are proposed, which allow calculating the efficiency of dust collection of contact stages, as well as the overall efficiency of a cyclone-vortex apparatus.

The results show the prospects of using devices of this design at heat power plants and other industries.

\section{References}

1. Matus, K., Nam, K.-M., Selin, N. E., Lamsal, L. N., Reilly, J. M., Paltsev, S. (2012). Health damages from air pollution in China. Global Environmental Change, 22 (1), 55-66. doi: http://doi.org/ 10.1016/j.gloenvcha.2011.08.006

2. Neira, M. (2016). Ambient air pollution: a global assessment of exposure and burden of disease. Geneva: WHO Document Production Services, 132.

3. Gedik, K., Imamoglu, I. (2011). A preliminary investigation of the environmental impact of a thermal power plant in relation to PCB contamination. Environmental Science and Pollution Research, 18 (6), 968-977. doi: http://doi.org/10.1007/ s11356-010-0430-z

4. Mishra, U. (2004). Environmental impact of coal industry and thermal power plants in India. Journal of Environmental Radioactivity, 72 (1-2), 35-40. doi: http://doi.org/10.1016/ $\mathrm{s} 0265-931 \mathrm{x}(03) 00183-8$

5. George, J., Masto, R. E., Ram, L. C., Das, T. B., Rout, T. K., Mohan, M. (2014). Human Exposure Risks for Metals in Soil Near a Coal-Fired Power-Generating Plant. Archives of Environmental Contamination and Toxicology, 68 (3), 451-461. doi: http://doi.org/10.1007/s00244-014-0111-x

6. Demirak, A., Balci, A., Dalman, Ö., TÜfekçı, M. (2005). Chemical Investigation of Water Resources Around the Yatagan Thermal Power Plant of Turkey. Water, Air, \& Soil Pollution, 162 (1-4), 171-181. doi: http://doi.org/10.1007/s11270-005-5999-3

7. Raptis, C. E., Pfister, S. (2016). Global freshwater thermal emissions from steam-electric power plants with once-through cooling systems. Energy, 97, 46-57. doi: http://doi.org/10.1016/ j.energy.2015.12.107

8. Hurets, L. L., Kozii, I. S., Miakaieva, H. M. (2017). Directions of the environmental protection processes optimization at heat power engineering enterprises. Journal of Engineering Sciences, 4 (2), g12-g16. doi: http://doi.org/10.21272/jes.2017.4(2).g12

9. Abdul-Wahab, S. A., Jupp, B. P. (2009). Levels of heavy metals in subtidal sediments in the vicinity of thermal power/desalination plants: a case study. Desalination, 244 (1), 261-282. doi: http://doi.org/10.1016/j.desal.2008.06.007

10. Raja, R., Nayak, A. K., Shukla, A. K., Rao, K. S., Gautam, P., Lal, B. (2015). Impairment of soil health due to fly ash-fugitive dust deposition from coal-fired thermal power plants. Environmental Monitoring and Assessment, 187 (11), 679. doi: http:// doi.org/10.1007/s10661-015-4902-y

11. Wang, X., Du, L. (2016). Study on carbon capture and storage (CCS) investment decision-making based on real options for China's coal-fired power plants. Journal of Cleaner Production, 112 (5), 4123-4131. doi: http://doi.org/10.1016/j.jclepro. 2015.07.112

12. Tock, L., Maréchal, F. (2015). Environomic optimal design of power plants with $\mathrm{CO}_{2}$ capture - Environomic optimal design of power plants with $\mathrm{CO}_{2}$ capture. International Journal of Greenhouse Gas Control, 39, 245-255. doi: http://doi.org/ 10.1016/j.ijggc.2015.05.022

13. Miller, B. G. (2011). Anatomy of a Coal-Fired Power Plant. Clean Coal Engineering Technology. Butterworth-Heinemann, 219-250. doi: http://doi.org/10.1016/b978-1-85617-710-8.00006-6

14. Phillips, H. W. (2000). Select the proper gas cleaning equipment. Chemical Engineering Progress, 96 (9), 19-38.

15. Hession, M. (1997). Incinerator and gas cleaning equipment overview. Health estate journal, 51 (8), 6-7.

16. Sutherland, K. (2007). Choosing equipment: Cleaning air and gas. Filtration \& Separation, 44 (1), 16-19. doi: http://doi.org/ 10.1016/s0015-1882(07)70020-4
17. Straus, V. (1981). Promyshlennaia ochistka gazov. Moscow: Khimiia, 616

18. Wu, X., Wu, K., Zhang, Y., Hong, Q., Zheng, C., Gao, X., Cen, K. (2017). Comparative life cycle assessment and economic analysis of typical flue-gas cleaning processes of coal-fired power plants in China. Journal of Cleaner Production, 142 (4), 3236-3242. doi: http://doi.org/10.1016/j.jclepro.2016.10.146

19. Omarkulov, P. K. (2003). Mekhanyzm vzaymodeistvyia potokov v hazozhydkostnoi systeme. Khimichna promyslovist Ukrainy, 2, 31-32.

20. Birger, M. I., Valdberg, A. Iu., Miagkov, B. I. et. al..; Rusanov, A. A. (Ed.) (1983). Spravochnik po pyle - i zoloulavlivaniiu. Moscow: Energoatomizdat, 312.

21. Gimbun, J., Choong, T. S. Y., Fakhru'l-Razi, A., Chuah, T. G. (2012). Prediction of the Effect of Dimension, Particle Density, Temperature, and Inlet Velocity on Cyclone Collection Efficiency. Jurnal Teknologi, 40, 37-50. doi: http://doi.org/10.11113/ jt.v40.421

22. Balabekov, O. S., Volnenko, A. A. (2015). Raschet $i$ konstruirovanie teplomassoobmennykh $i$ pyleulavlivaiuschikh apparatov s podvizhnoi i reguliarnoi nasadkoi. Shymkent, 184.

23. Balabekov, O. S., Petin, V. F. (2000). Zakonomernost vzaimodeistviia vikhrei, voznikaiuschikh pri otryonom obtekanii potokom gaza ili zhidkosti diskretno raspolozhennykh vdol nego tel. Svidetelstvo o nauchnom otkrytii No. 144. Moscow: Mezhdunarodnaia assotsiatsiia avtorov nauchnykh otkrytii.

24. Kouzov, P. A., Skriabina, L. Ia. (1983). Metody opredeleniia fiziko-khimicheskikh svoisto promyshlennykh pylei. Leningrad: Khimiia, 143.

25. Sharygin, M. P. (1992). Razrabotka i raschet ustroisto dlia razrusheniia otlozhenii i pyleulavlivaniia s upravliaemym vikhrevym potokom. Moscow: 480.

26. Volnenko, A. A. (1999). Nauchnye osnovy razrabotki i rascheta vikhrevykh massoobmennykh i pyleulavlivaiuschikh apparatov. Shymkent, 300.

27. Leith, D., Licht, W. (1972). The Collection Efficiency of Cyclone-Type Particle Collectore - A New Theoretical Approach. AICh, Sympsium Series, 68 (126), 196-206.

28. Uzhov, V. N., Valdberg, A. Iu., Miagkov, B. I., Reshidov, I. K. (1981) Ochistka promyshlennykh gazov ot pyli. Moscow: Khimiia, 390.

Andrei Torsky, PhD, Department of Production Machines and Equipment, M. Auezov South Kazakhstan State University, Shymkent, Kazakhstan, ORCID: http://orcid.org/0000-0001-9553-2496, e-mail:niimm@mail.ru

Alexander Volnenko, Doctor of Technical Sciences, Professor, Head of Department of Production Machines and Equipment, M. Auezov South Kazakhstan State University, Shymkent, Kazakhstan, ORCID: http:// orcid.org/0000-0001-6800-9675, e-mail:nii_mm@mail.ru

Leonid Plyatsuk, Doctor of Technical Sciences, Professor, Head of Department of Ecology and Environmental Protection Technologies, Sumy State University, Sumy, Ukraine, ORCID: http://orcid.org/ 0000-0001-7032-1721, e-mail: l.plyacuk@ecolog.sumdu.edu.ua

Larysa Hurets, Doctor of Technical Sciences, Associate Professor, Department of Ecology and Environmental Protection Technologies, Sumy State University, Sumy, Ukraine, ORCID: http://orcid.org/ 0000-0002-2318-4223, e-mail: l.gurets@ecolog.sumdu.edu.ua

Daulet Zhumadullayev, PhD, Lecturer, Department of Production Machines and Equipment, M. Auezov South Kazakhstan State University, Shymkent, Kazakhstan, ORCID: http://orcid.org/00000002-6552-2817,e-mail: daulet_ospl@mail.ru

Abay Abzhabparov, Lecturer, Department of Production Machines and Equipment, M. Auezov South Kazakhstan State University, Shymkent, Kazakhstan, ORCID: http://orcid.org/0000-0002-6326-8421, e-mail:daulet_ospl@mail.ru 